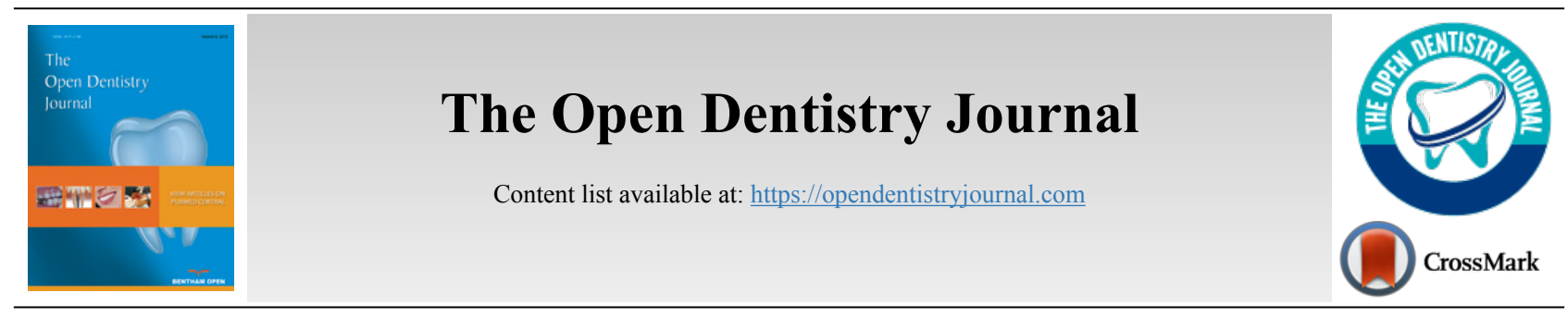

RESEARCH ARTICLE

\title{
Prevalence of Color Vision Deficiency among Dental Practitioners and its Effect on Shade Matching Ability
}

\author{
Abdulhaq Suliman ${ }^{1}$, Tholfikar Al-Abdali ${ }^{1}$, Mohammed Taslimi $^{1}$ and Ahmad Abdo ${ }^{1, *}$ \\ ${ }^{I}$ Department of Restorative Dentistry, College of Dentistry, Ajman University, Ajman, UAE
}

\begin{abstract}
:
Objective:

Shade selection is a crucial step in achieving aesthetically-pleasing restorations, and it is affected by the dentist's ability to match the shade of the patient's teeth. Color Deficiency Disease (CVD) has been thought to be a potential factor affecting color perception. The study aims to find the prevalence of CVD between dentists and dental students and to evaluate its effect on shade matching ability.

Methods:

A sample of 319 dentists and dental students in the College of Dentistry at Ajman University, Ajman, UAE was examined with the Ishihara test to find the prevalence of CVD. Then participants with CVD were tested for shade matching ability, and were compared to participants with normal color vision with the same gender and qualification level. They were asked to match 10 random composite samples with different shades to a custom shade guide made from the same composite material. A score was calculated, representing the number of correct answers they achieved.

Results:

The results showed that 8 out of 143 males $(5.6 \%)$ had CVD, and 0 out of 176 females had CVD. There was no significant difference in the score of shade matching test between participants with CVD and participants with normal color vision $(\mathrm{p}=0.075)$.

Conclusion:

Males showed a higher prevalence of color vision deficiency than females. CVD had no significant effect on shade matching ability.
\end{abstract}

Keywords: Color Vision Deficiency, Shade selection, Composite, CVD, Aesthetics, Color Blindness.

\begin{tabular}{|l|l|l|r}
\hline Article History & Received: July 12, 2020 & Revised: August 20, 2020 & Accepted: August 24, 2020
\end{tabular}

\section{INTRODUCTION}

Dental appearance is an important characteristic in defining the attractiveness of the face, and a person's smile has psychological importance and plays a key role in human social interactions. There are some significant aspects affecting overall dental appearance like tooth color, position and shape, quality of restorations and the general arrangement of the dentition, specially of the anterior teeth $[1,2]$. It has been shown that treatments improving dental aesthetics increase the patients' quality of life and psychological status [3, 4].

Tooth color is one of the most important factors as people in general desire for pearly white teeth $[1,5]$. In addition, pati-

\footnotetext{
* Address correspondence to this author at the Department of Restorative Dentistry, College of Dentistry, Ajman University, University St, Al Jurf, Ajman, Ajman 346, United Arab Emirates; Tel: +971507767311;

E-mail: ahmad.abdo@ajman.ac.ae
}

ents are now more concerned about matching the shade of their aesthetic replacements to their teeth more than the quality of the restoration $[6,7]$. When restoring a tooth, an accurate shade selection of the restoration material is a very crucial step to achieve a successful aesthetic restoration, whether it is a crown, a veneer, or a composite restoration $[6,8]$. Shade selection can be done using the visual method or using instruments and equipment. Both methods have their advantages and disadvantages, but the visual method is still the most used because of its simplicity and lower cost [9 - 13]. However, color perception might vary from one person to another [10 - 14], and this can affect the aesthetic quality of the final restoration and the patient's satisfaction. The difference in color perception can have numerous causes such as eye fatigue, background color, quality of light, inexperience, and hereditary deficiencies in color perception [15]. 
Color Vision Deficiency (CVD) is a common defect of the human eyes, that affect the perception of color. Studies showed that the prevalence in males is much higher than females [16, 17]. It occurs due to missing one or more of the three groups of color cones cells, which are located within the retina of the eye, and these cones are mainly sensitive to red, green, and blue colors [16 - 19]. It can be acquired or hereditary. Acquired color deficiency, which may be due to macular disease, optic nerve diseases, degeneration of retina, toxins, and ageing can affect one or both eyes to different degrees. Whereas, the hereditary color deficiency is genetic and affects both the eyes to the same degree [20]. CVD can cause changes in color vision ranging from mild deficiency to total inability to detect color. CVD can be divided into three categories; Monochromacy, also known as color-blind, which is a complete absence of color vision, and it is the least common type. Dichromacy, which is less severe than Monochromacy, and is divided into sub-categories; Protanopia and Deuteranopia, which are known as red-green defects, and Tritanopia, which is known as a blue-yellow defect. The third category is called Anomalous Trichromatism, where subjects are sensitive to all three hues [19-22].

CVD can cause difficulties in everyday life. One study showed that $75 \%$ of 102 participants with CVD reported some degree of difficulty, and there was a correlation between the proportion reporting difficulty and the severity of CVD [23]. It was also shown that professionals in the medical field with CVD were having difficulties in some aspects of their work, specially while doing different types of examinations and diagnosis [23].

There are various tests for CVD, but the most popular one is the Ishihara test, which is less time consuming and less expensive than the other tests [22]. The Ishihara test is a color perception test for red-green color deficiencies, which are the most common type [18, 24 - 26]. It consists of 38 Pseudoisochromatic Plates (PIP), which are figures or patterns that show a circle made of dots varying in sizes and color, and within the circle, a digit or a curved line made of different color dots. For a normal person with no CVD, the digit or the line stand out clearly from its background. When administering the test, observers are required to identify the pattern or figure embedded in the plate $[25,26]$.

The aim of this study was to determine the prevalence of color deficiency disease among dentists and dental students in the College of Dentistry at Ajman University, Ajman, United Arab Emirates, and to evaluate the ability to select suitable shades for esthetic restorations for participants with CVD and compare them to participants with normal color vision.

\section{METHODS}

Ethical approval was obtained from the ethical committee of the College of Dentistry at Ajman University with reference number (RD-2017/18-06-S). Informed consent was taken from all participants. The study was divided into two parts; the first part involved screening dentists and dental students for CVD while establishing an estimated prevalence of CVD. The second part involved finding the effect of CVD on shade matching of composite resin.
A sample of 319 participants with age ranging from 20 to 60 years was tested with a color vision test (The Ishihara test). All participants were practicing restorative dentistry and were involved in the shade selection of different types of restorations. The sample consisted of 143 (44.8\%) male participants and $176(55.2 \%)$ female participants. The sample involved dental students in clinical years $\left(4^{\text {th }}, 5^{\text {th }}\right.$ and internship years), general dental practitioners (GDP), and dental specialists from restorative and prosthodontic departments. Participants were asked to identify the plates of the Ishihara test in a controlled environment with a distance of $75 \mathrm{~cm}$ and daylight, as suggested in the Ishihara user manual. The test consisted of 38 plates that were divided into two groups; the first group of 25 plates had a digit inside of a background. Participants were asked to identify each number within three seconds and record their answers on a test paper. The second group (plates 26 to 38) had a continuous line instead of numbers (snake-shaped lines). The participants were asked to trace and follow these lines and record the color of the lines on the test paper. By the end of each test, the participant's answers were compared to the list of the correct answers, as it was mentioned in the Ishihara user manual. Then data was collected, and participants with CVD were identified.

During the second part of the study, the aim was to measure the accuracy of shade matching ability of participants with CVD, and compare them with participants with normal color vision within the same gender and qualification level. Since only male participants were found to have CVD in the first part, the second part was done only for male participants. Eight male participants were found to have CVD. The participants with CVD were categorized into four groups according to their qualification level $\left(4^{\text {th }}\right.$-year students, $5^{\text {th }}$-year students, Internship students and GPs). Ten participants with normal color vision were selected randomly from each qualification group making a total of 40 participants with normal color vision. One of the participants with CVD declined to join the second part. The total number of participants with CVD was 7 participants. The results of those 7 participants were compared to the results of the 40 participants who were with normal color vision.

In this test, each participant was provided a glass slab that contained 10 cured composite resin samples (ZENIT Nano, President Dental, Germany). The samples were made into the shape and size of the maxillary central incisor, and each sample was made from a different shade of the same composite. The following shades were used (A1, A2, A3, A3.5, A4, B1, B2, B3, C2, and C3). The samples were numerically coded randomly (Fig. 1). A custom shade guide was made from the same composite material using "My Shade Guide Mini Kit" (3M ESPE, St. Paul, MN, USA). The shade guide consisted of 10 composite samples that were marked with their shades, and they were made into the same size and shape of the composite samples on the glass slab (Fig. 1). Vita Easyshade Vunit (VITA Zahnfabrik, Bad Sackingen, Germany) was used to confirm that the composite samples on the glass slab and the samples on the custom shade guide were matching in the shade. Initially, 20 composite samples were made, but then they were reduced to 10 to make the test less difficult to the participants; this explains the numbers on the samples on the glass-slab (Fig. 
1). All 47 participants were asked to match between the composite samples and the custom shade guide, and record their answers on the test paper. Then the correct answers were calculated for each participant, and a score was given out of 10 .

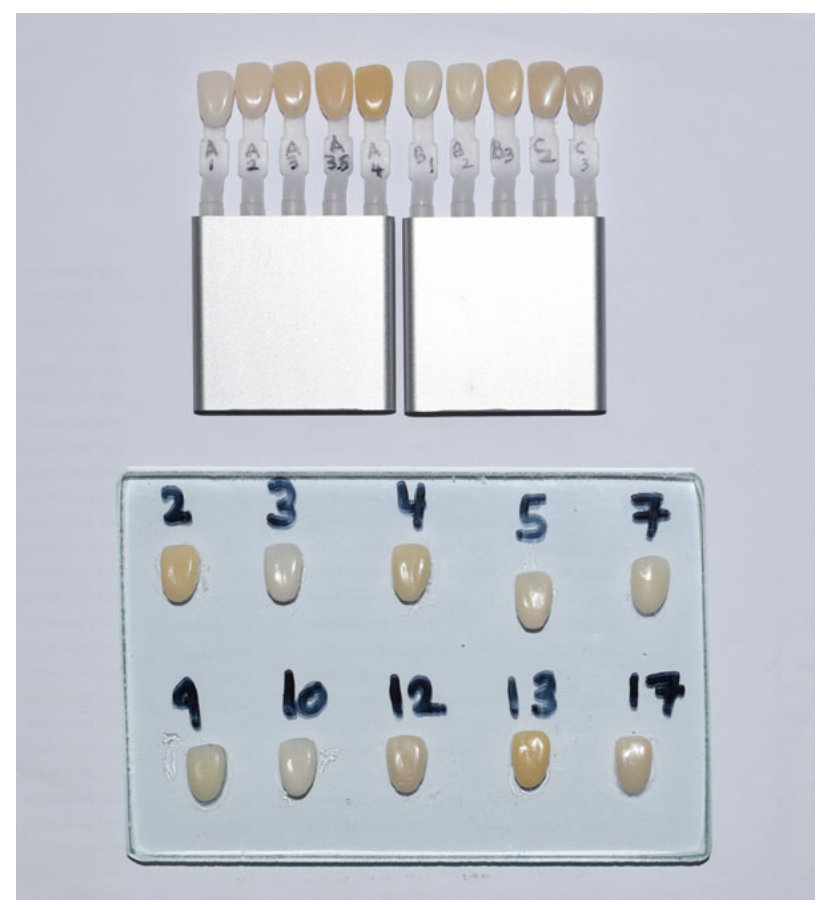

Fig (1). A glass-slab with 10 cured composite samples randomly numbered, and a custom shade guides made from the same composite material (ZENIT Nano, President Dental, Germany).

Statistical analysis was conducted at a 5\% significance level using (SPSS Inc., version 20.0; Chicago, IL, USA). Chisquare test was used to compare the test scores of the CVD group and the normal color vision group.

Table 1. Scores of the shade matching ability test, comparing the normal color vision group and CVD group.

\begin{tabular}{|l|c|c|c|c|c|c|}
\hline Groups & $\begin{array}{l}\text { Total } \\
\mathbf{N}\end{array}$ & Minimum & Maximum & Range & Mean & $\begin{array}{l}\text { Standard } \\
\text { Deviation }\end{array}$ \\
\hline $\begin{array}{l}\text { Normal } \\
\text { color } \\
\text { vision }\end{array}$ & 40 & 3 & 10 & 7 & 7.75 & 1.78 \\
\hline CVD & 7 & 4 & 8 & 4 & 5.14 & 1.49 \\
\hline
\end{tabular}

-The test involved matching 10 composite samples, every correct answer yield 1 point (minimum 0, maximum 10).

\section{RESULTS}

Out of the 319 participants that were tested in the first part of the study, 143 were males (44.8\%) and 176 were females (55.2\%). The results showed that 8 males out of $143(5.6 \%)$ were with CVD, and no females were found with CVD. All of the 8 males had the red-green type of CVD. Two of them were $4^{\text {th }}$-year students, three were $5^{\text {th }}$-year students, one was an internship student, and two were GDP clinical instructors. In the second part, a sample of 47 participants (males only) was tested for shade matching ability of composite, including 7 participants with CVD and 40 with normal color vision. The results showed that participants with normal color vision $(n=40)$ had an average test score of 7.75 when matching the shade of the random composite samples to the custom shade guide, while the participants with CVD $(n=7)$ had an average of 5.14. Table 1 shows the minimum, maximum, mean and standard deviation of the two groups. However, the statistical analysis using Chi-square showed that there was no significant difference between the normal vision group and the CVD group $(\mathrm{p}=0.075)$.

\section{DISCUSSION}

The ability to match the shade of tooth-colored restorations to that of the natural teeth is very important to any restorative dentist. Ideally, the restoration should match the exact shape and color of the patient's natural tooth. Color perception can differ between individuals due to multiple factors, and this can affect shade selection [27]. Color vision deficiency, therefore, might affect dental practitioners when they want to match the shade of patient's teeth. The results showed that the prevalence of CVD among males (5.6\%) was higher than females $(0 \%)$. It was shown in multiple researches that the prevalence of CVD in males is much higher than females $[16-18,22]$. The prevalence of CVD in the UK was found to be $8 \%$ in males and $0.5 \%$ in females [23]. Color vision defects are inherited as $\mathrm{X}$ linked recessive disorder, which explains its predominance among the males.

The Ishihara test does not identify individuals with full color-blindness; individuals diagnosed by the Ishihara test might still identify the primary colors correctly. Other methods like the Naegelanamaloscope test and the Franseworth-Munsell hundred hue test are also available to test for color vision. These tests are more accurate but more time-consuming. Therefore, not appropriate for mass screening. The Ishihara test was selected because it is easier and quicker to perform, and it is still accurate enough for the assessment of CVD in mass screening $[22,25]$.

The results of this study found that there is no significant difference in shade matching ability between participants with CVD and participants with normal color vision. This confirms the results of a study done in 2017 that has found similar results [16]. However, other studies found a difference and that individuals with normal color vision performed better in shade matching than individuals with CVD [28, 29]. Therefore, more research might be required with larger populations to reach a definitive conclusion. Nevertheless, it is recommended that color vision screening tests should be done regularly to identify dentists with CVD, and their shade matching ability should be tested, and in case it was found to be inferior, it is advised that an assistant should help those dentists when it comes to shade selection. In addition, the use of electronic shade guides and spectrophotometers can be a useful tool in the shade matching of teeth to help reduce possible errors.

Moreover, it should be pointed that the overall shade matching of the participants was not optimal even for those with normal color vision as they scored an average of 7.75 out of 10 , which means their shade matching was not accurate $22.5 \%$ of the time. This can be explained by the lower experience, as most of the participants were students or residents. It has been shown that the majority of dentists are 
using visual shade matching, and it was reported that there was a high rate of error [30]. Shade matching exercises and training for dental students, dentists and dental assistants can be beneficial in improving their shade matching ability leading to better aesthetic restorations and increasing patients' satisfaction.

\section{CONCLUSION}

Within the limitations of this study, it was concluded that males showed a higher prevalence of Color Vision Deficiency (CVD) than females. There was no significant difference in the shade matching ability of composite resin between dentists with CVD and dentists with normal color vision.

\section{ETHICS APPROVAL AND CONSENT TO PARTI- CIPATE}

Ethical approval was obtained from the ethical committee of the College of Dentistry at Ajman University, UAE with reference number (RD-2017/18-06-S).

\section{HUMAN AND ANIMAL RIGHTS}

No animals were used in this research. All human research procedures followed were in accordance with the ethical standards of the committee responsible for human experimentation (institutional and national), and with the Helsinki Declaration of 1975, as revised in 2013.

\section{CONSENT FOR PUBLICATION}

Informed consent was taken from all participants.

\section{AVAILABILITY OF DATA AND MATERIALS}

The datasets generated during and/or analyzed during the current study are available from the corresponding author $[\mathrm{A}, \mathrm{A}]$ on reasonable request.

\section{FUNDING}

None.

\section{CONFLICT OF INTEREST}

The authors declare no conflict of interest, financial or otherwise.

\section{ACKNOWLEDGEMENTS}

Special thanks to Dr. Mohammed Hadi, a specialist in ophthalmology, and Mrs. Hanine Bou Antoun from statistics department, for their help in points related to their specialties.

\section{REFERENCES}

[1] Qualtrough AJ, Burke FJ. A look at dental esthetics. Quintessence Int 1994; 25(1): 7-14. [PMID: 8190886]

[2] Van der Geld P, Oosterveld P, Van Heck G, Kuijpers-Jagtman AM. Smile attractiveness. Self-perception and influence on personality. Angle Orthod 2007; 77(5): 759-65.

[http://dx.doi.org/10.2319/082606-349] [PMID: 17685777]

[3] John MT, Slade GD, Szentpétery A, Setz JM. Oral health-related quality of life in patients treated with fixed, removable, and complete dentures 1 month and 6 to 12 months after treatment. Int J Prosthodont 2004; 17(5): 503-11. [PMID: 15543905]
[4] Grossmann AC, Hassel AJ, Schilling O, Lehmann F, Koob A, Rammelsberg P. Treatment with double crown-retained removable partial dentures and oral health-related quality of life in middle- and high-aged patients. Int J Prosthodont 2007; 20(6): 576-8. [PMID: 18069364]

[5] Samorodnitzky-Naveh GR, Geiger SB, Levin L. Patients' satisfaction with dental esthetics. J Am Dent Assoc 2007; 138(6): 805-8. [http://dx.doi.org/10.14219/jada.archive.2007.0269] [PMID: 17545270]

[6] Hall NR. Tooth colour selection: The application of colour science to dental colour matching. Aust Prosthodont J 1991; 5: 41-6. [PMID: 1812938]

[7] Fondriest J. Shade matching in restorative dentistry: The science and strategies. Int J Periodontics Restorative Dent 2003; 23(5): 467-79. [PMID: 14620121]

[8] Joiner A. Tooth colour: A review of the literature. J Dent 2004; 32(Suppl. 1): 3-12.

[http://dx.doi.org/10.1016/j.jdent.2003.10.013] [PMID: 14738829]

[9] Klemetti E, Matela AM, Haag P, Kononen M. Shade selection performed by novice dental professionals and colorimeter. J Oral Rehabil 2006; 33(1): 31-5.

[http://dx.doi.org/10.1111/j.1365-2842.2006.01531.x] [PMID: 16409514]

[10] Hammad IA. Intrarater repeatability of shade selections with two shade guides. J Prosthet Dent 2003; 89(1): 50-3.

[http://dx.doi.org/10.1067/mpr.2003.60] [PMID: 12589286]

[11] Judeh A, Al-Wahadni A. A comparison between conventional visual and spectrophotometric methods for shade selection. Quintessence Int 2009; 40(9): e69-79.

[PMID: 19862392]

[12] Small BW. Shade selection for restorative dentistry. Gen Dent 2006; 54(3): 166-7.

[PMID: 16776406]

[13] Dagg H, O'Connell B, Claffey N, Byrne D, Gorman C. The influence of some different factors on the accuracy of shade selection. J Oral Rehabil 2004; 31(9): 900-4.

[http://dx.doi.org/10.1111/j.1365-2842.2004.01310.x]

[PMID: 15369473]

[14] Culpepper WD. A comparative study of shade-matching procedures. J Prosthet Dent 1970; 24(2): 166-73.

[http://dx.doi.org/10.1016/0022-3913(70)90140-X] [PMID: 5269632]

[15] Miller L. Organizing color in dentistry. J Am Dent Assoc 1987; (Spec No): $26 \mathrm{E}-40 \mathrm{E}$.

[http://dx.doi.org/10.14219/jada.archive.1987.0315] [PMID: 2447140]

[16] Khosla A. Maini, A.Wangoo, A. Singh, S.\&Mehar, D. Prevalence of colour vision anomalies. J Clin Diagn Res 2017; 11(1): 33-6. [PMID: 28274040]

[17] Balasundaram R, Reddy SC. Prevelance of colour vision deficincy among medical students and health personnel. Malays Fam Physician 2006; 1(2-3): 52-3. [PMID: 27570586]

[18] Yousuf W, Quraeshi S, Khan M, Murtaza S. Prevalence of colorblindness among practitioners of esthetic dentistry in Karachi, Pakistan. Int J Clin Dent 2015; 8(1): 37-41.

[19] Al-Aqtum MT, Al-Qawasmeh MH. Prevalence of colour blindness in young Jordanians. Ophthalmologica 2001; 215(1): 39-42. [http://dx.doi.org/10.1159/000050824] [PMID: 11125268]

[20] Cohen J. Weighted kappa: Nominal scale agreement with provision for scaled disagreement or partial credit. Psychol Bull 1968; 70(4): 213-20.

[http://dx.doi.org/10.1037/h0026256] [PMID: 19673146]

[21] Wasson W, Schuman N. Color vision and dentistry. Quintessence Int 1992; 23(5): 349-53. [PMID: 1502311]

[22] Naik A, Pai R. Color Blindness in dental students and staff- and obstacle in shade selection for restorations. Annals and Essences of Dentistry 2010; 11: 25-8.

[23] Spalding JA. Colour vision deficiency in the medical profession. $\mathrm{Br} \mathrm{J}$ Gen Pract 1999; 49(443): 469-75.

[PMID: 10562750]

[24] Bamise CT, Esan TA, Akeredolu PA, Oluwatoyin O, Oziegbe EO. Color vision defect and tooth shade selection among Nigerian dental practitioners. Rev Clín Pesq Odontol 2017; 3(3): 175-82.

[25] Marey HM. Semary, NA. \&Mandour, SS. Ishihara electronic color blindness test: An evaluation study. Ophthalmol Res: Int J 2015; 3(3): 67-75.

[26] Birch J. Worldwide prevalence of red-green color deficiency. J Opt 
Soc Am A Opt Image Sci Vis 2012; 29(3): 313-20. [http://dx.doi.org/10.1364/JOSAA.29.000313] [PMID: 22472762]

[27] Al-Wahadni A, Ajlouni R, Al-Omari Q, Cobb D, Dawson D. Shadematch perception of porcelain-fused-to-metal restorations: A comparison between dentist and patient. J Am Dent Assoc 2002; 133(9): $1220-5$

[http://dx.doi.org/10.14219/jada.archive.2002.0363] [PMID: 12356253]

[28] Gokce HS, Piskin B, Ceyhan D, Gokce SM, Arisan V. Shade matching performance of normal and color vision-deficient dental professionals with standard daylight and tungsten illuminants. J Prosthet Dent 2010;
103(3): 139-47.

[http://dx.doi.org/10.1016/S0022-3913(10)60020-0]

[PMID: 20188236]

[29] Vafaee F, Rakhshan V, Vafaei M, Khoshhal M. Accuracy of shade matching performed by colour blind and normal dental students using 3D Master and Vita Lumin shade guides. Eur J Prosthodont Restor Dent 2012; 20(1): 23-5.

[PMID: 22474932]

[30] Mazur M, et al. The influence of dental occlusion on spectrophotometric tooth color determinations. Open Dent J 2020; 14: 247-54.

[http://dx.doi.org/10.2174/1874210602014010247]

\section{(C) 2020 Suliman et al.}

This is an open access article distributed under the terms of the Creative Commons Attribution 4.0 International Public License (CC-BY 4.0), a copy of which is available at: (https://creativecommons.org/licenses/by/4.0/legalcode). This license permits unrestricted use, distribution, and reproduction in any medium, provided the original author and source are credited. 